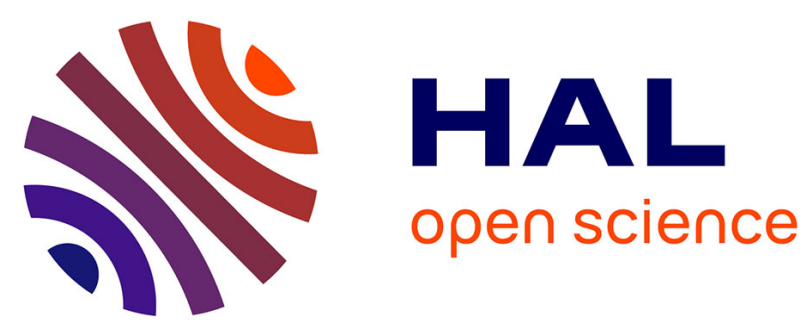

\title{
Sigma Convergence versus Beta Convergence: Evidence from U.S. County-Level Data
}

\author{
Andrew T Young, Matthew J Higgins, Daniel Levy
}

\section{To cite this version:}

Andrew T Young, Matthew J Higgins, Daniel Levy. Sigma Convergence versus Beta Convergence: Evidence from U.S. County-Level Data. Journal of Money, Credit and Banking, 2008, 40 (5), pp.10831093. 10.1111/j.1538-4616.2008.00148.x . hal-02387475

\section{HAL Id: hal-02387475 \\ https://hal.science/hal-02387475}

Submitted on 29 Nov 2019

HAL is a multi-disciplinary open access archive for the deposit and dissemination of scientific research documents, whether they are published or not. The documents may come from teaching and research institutions in France or abroad, or from public or private research centers.
L'archive ouverte pluridisciplinaire HAL, est destinée au dépôt et à la diffusion de documents scientifiques de niveau recherche, publiés ou non, émanant des établissements d'enseignement et de recherche français ou étrangers, des laboratoires publics ou privés. 


\title{
Sigma Convergence versus Beta Convergence: Evidence from U.S. County-Level Data
}

\author{
Andrew T. Young* \\ Department of Economics \\ University of Mississippi \\ University, MS 38677 \\ atyoung@olemiss.edu
}

Tel: 662-915-5829, Fax: 404-894-6030

\author{
Matthew J. Higgins \\ College of Management \\ Georgia Institute of Technology \\ Atlanta, GA 30308-0520 \\ mhiggins@mgt.gatech.edu
}

Tel: 404-894-4368. Fax: 404-894-6030

\author{
Daniel Levy \\ Department of Economics \\ Bar-Ilan University \\ Ramat-Gan 52900, Israel \\ levyda@mail.biu.ac.il \\ Tel: +972-3-531-8331, Fax: +972-3-535-3180
}

Last Revision: January $23^{\text {nd }}, 2007$

JEL Codes: O40, O11, O18, R11

Key Words: sigma-convergence, beta-convergence, Solow growth model, speed of convergence, balanced growth, U.S. county-level data, income distribution, Gini coefficient, income equality

\footnotetext{
* Corresponding Author. We are grateful to the anonymous referee for constructive comments and suggestions. In addition, we thank Jordan Rappaport for kindly sharing with us some of his data and computer codes and for providing helpful suggestions throughout the study. All errors are ours.
} 


\title{
Sigma Convergence versus Beta Convergence: Evidence from U.S. County-Level Data
}

\begin{abstract}
In this paper we outline (i) why $\sigma$-convergence may not accompany $\beta$-convergence, (ii) discuss evidence of $\beta$-convergence in the U.S., and (iii) use U.S. county-level data containing over 3,000 cross-sectional observations to demonstrate that $\sigma$-convergence cannot be detected at the county-level across the U.S., or within the large majority of the individual U.S. states considered separately. Indeed, in many cases statistically significant $\sigma$-divergence is found.
\end{abstract}




\section{Introduction}

One can distinguish between two types of convergence in growth empirics: $\sigma$ convergence and $\beta$-convergence. When the dispersion of real per capita income (henceforth, simply "income") across a group of economies falls over time, there is $\sigma$ convergence. When the partial correlation between growth in income over time and its initial level is negative, there is $\beta$-convergence.

By the "convergence literature," economists typically refer to the large literature, typified by the seminal papers by Barro and Sala-i-Martin (1992) and Mankiw et al. (1992), exploring $\beta$-convergence. Sala-i-Martin (1996, p. 1326), surveying this literature, concludes that "the estimated speeds of $[\beta$ - $]$ convergence are so surprisingly similar across [cross-sectional] data sets, that we can use a mnemonic rule: economies converge at a speed of two percent per year." In other words, economies close the gap between present levels of income and balanced growth levels by, on average, 2 percent annually. Panel data studies find even higher rates of $\beta$-convergence - see Islam (1995) and Evans (1997a) - as do the county-level U.S. studies of Higgins et al. (2006) and Young et al. (2007).

Despite the literature's stress on $\beta$-convergence, economists have acknowledged that it is not a sufficient condition for $\sigma$-convergence. (For an early acknowledgement of this idea see Barro and Sala-i-Martin (1992, pp. 227-228)) Indeed, Quah (1993) and Friedman (1992) both suggest that $\sigma$-convergence is of greater interest since it speaks directly as to whether the distribution of income across economies is becoming more equitable.

In this paper we demonstrate that $\beta$-convergence is a necessary but not sufficient condition for $\sigma$-convergence. Then we discuss evidence of $\beta$-convergence in the U.S. 
using county-level data covering 1970 to 1998 and containing over 3,000 cross-sectional observations. We demonstrate, using the same data, that $\sigma$-convergence cannot be detected during that time period in the U.S. or within the large majority of the individual U.S. states considered separately. Indeed, in many cases statistically significant $\sigma$ divergence is found.

The paper is organized as follows. Section II demonstrates why $\sigma$-convergence need not accompany $\beta$-convergence. Section III describes the U.S. county-level data that is the basis for our present ( $\sigma$-convergence) and previously reported ( $\beta$-convergence) results. Section IV discusses the existing empirical evidence indicating that $\beta$ convergence exists in the U.S. Section V demonstrates that $\sigma$-convergence did not occur across the U.S., or within a majority of the individual U.S. states, from 1970 to 1998. Section VI reports Gini coefficients for the same county-level data that are consistent with a lack of $\sigma$-convergence. Section VII concludes.

\section{II. $\beta$-Convergence versus $\sigma$-Convergence}

Following Sala-i-Martin's (1996) exposition, assume that $\beta$-convergence holds for economies $i=1, \ldots, N .^{1}$ Natural log-income of the $i$-th economy can be approximated by

$$
\ln \left(y_{i t}\right)=a+(1-\beta) \ln \left(y_{i, t-1}\right)+u_{i t},
$$

where $0<\beta<1$ and $u_{i t}$ has mean zero, finite variance, $\sigma_{u}^{2}$, and is independent over $t$ and

$i$. Because $a$ is assumed constant across economies, balanced growth paths are identical. ${ }^{2}$ Manipulating (1) yields,

\footnotetext{
${ }^{1}$ Barro and Sala-i-Martin (1991) present a similar exposition and intuitive discussion. More recently, Furceri (2005) presents a related demonstration based on an OLS estimator of the coefficient on initial income.
} 


$$
\ln \left(\frac{y_{i t}}{y_{i, t-1}}\right)=a-\beta \ln \left(y_{i, t-1}\right)+u_{i t} .
$$

Thus, $\beta>0$ implies a negative correlation between growth and initial log income.

The sample variance of log income in $t$ is given by

$$
\sigma_{t}^{2}=\left(\frac{1}{N}\right) \sum_{i=1}^{N}\left[\ln \left(y_{i t}\right)-\mu_{t}\right]^{2}
$$

where $\mu_{t}$ is the sample mean of $(\log )$ income. The sample variance is close to the

population variance when $N$ is large, and (1) can be used to derive the evolution of $\sigma_{t}^{2}$ :

$$
\sigma_{t}^{2} \cong(1-\beta)^{2} \sigma_{t-1}^{2}+\sigma_{u}^{2}
$$

Only if $0<\beta<1$ is the difference equation stable, so $\beta$-convergence is necessary for $\sigma$ convergence. ${ }^{3}$ Given $0<\beta<1$, the steady-state variance is,

$$
\left(\sigma^{2}\right)^{*}=\frac{\sigma_{u}^{2}}{1-(1-\beta)^{2}} \text {. }
$$

Thus, the cross-sectional dispersion falls with $\beta$ but rises with $\sigma_{u}^{2}$. Combining (3) and

(4) yields,

$$
\sigma_{t}^{2}=(1-\beta)^{2} \sigma_{t-1}^{2}+\left[1-(1-\beta)^{2}\right]\left(\sigma^{2}\right)^{*},
$$

which is a first-order linear difference equation with constant coefficients. Its solution is given by,

\footnotetext{
${ }^{2}$ This is the case of absolute $\beta$-convergence; average growth rates of poor economies are unambiguously greater than those of rich economies. Allowing for different $a_{i} \mathrm{~s}, 0<\beta<1$ would imply the case of conditional $\beta$-convergence; the average growth rate of an economy is an increasing function of its distance from its balanced growth level of income. This is a weaker case of $\beta$-convergence and increases the set of possible scenarios where it does not imply $\sigma$-convergence. See the discussion at the end of this section. ${ }^{3}$ If $\beta \leq 0$ the variance increases over time. If $\beta=1$ the variance is constant and if $\beta>1$ the partial correlation between (log) income and its previous-period value would be negative and the series would oscillate, potentially from positive to negative values and back (making little economic sense).
} 


$$
\sigma_{t}^{2}=\left(\sigma^{2}\right)^{*}+(1-\beta)^{2 t}\left[\sigma_{0}^{2}-\left(\sigma^{2}\right)^{*}\right]+c(1-\beta)^{2 t}
$$

where $c$ is an arbitrary constant. Thus, as long as $0<\beta<1$, we have $|1-\beta|<1$, which implies that

$$
\lim _{t \rightarrow \infty}(1-\beta)^{2 t}=0
$$

This ensures the stability of $\sigma_{t}^{2}$ because it implies that,

$$
\lim _{t \rightarrow \infty} \sigma_{t}^{2}=\left(\sigma^{2}\right)^{*}
$$

Moreover, since $(1-\beta)>0$, the approach to $\left(\sigma^{2}\right)^{*}$ is monotonic.

It follows, therefore, that the variance will increase or decrease towards its steadystate value depending on the initial $\sigma_{0}^{2}$. Intuitively, economies can be $\beta$-converging towards one another while, at the same time, random shocks are pushing them apart. Despite $\beta$-convergence, if the initial dispersion of income levels is, by chance, small relative to the variance of random shocks then the dispersion of incomes will converge towards its steady-state value from below. ${ }^{4}$

Other scenarios where $\beta$-convergence does not imply $\sigma$-convergence arise when the parameter $a$ varies across economies. ${ }^{5}$ Intuitively, consider two economies, A and B, where both economies begin at the same level of income. However, assume that B begins on its balanced growth path while A begins far below its balanced growth path, and assume that $\beta$-convergence holds. The initial variance $\left(\sigma_{0}^{2}\right)$ will be zero, but $\sigma_{t}^{2}$

\footnotetext{
${ }^{4}$ Note in (6) that the parameter $\beta$ governs the speed at which the variance approaches its steady-state value because, according to (1), it governs how long the effect of shocks persist.

${ }^{5}$ This represents the case of conditional $\beta$-convergence. In empirical applications the $a_{i}$ s are often modeled as linear functions of various economic and/or socio-demographic variables available to the researcher, e.g., see Table 1 in Higgins et al. (2006).
} 
will grow over time as A grows faster than B and approaches a higher balanced growth path. Indeed, $\beta$-convergence is the reason for the increasing variance. ${ }^{6}$

\section{U.S. County-Level Data}

This paper utilizes the U.S. county-level data used by Higgins et al. (2006) and Young et al. (2007) to study income growth from 1970 to 1998 . The data set includes 3,058 county-level observations, and 50 individual state samples of various sizes, also at the county-level. See Figure 1.

The personal income measure we use is the definition used by the U.S. Bureau of Economic Analyses (BEA). It is adjusted to be net of government transfers and is expressed in per capita 1992 dollars using the U.S. GDP deflator. Population measures from the U.S. Census are used to construct per capita amounts. Real per capita income levels are expressed as natural logs and values are considered for both 1970 and $1998 .^{7}$

The definitions that are used for the components of personal income at the countylevel are essentially the same as those used for national measures. ${ }^{8}$ For example, the BEA defines "personal income" as the sum of wage and salary disbursements, other labor income, proprietors' income (with inventory valuation and capital consumption adjustments), rental income (with capital consumption adjustment), personal dividend income and personal interest income.

\footnotetext{
${ }^{6}$ In real economies, $\sigma$-convergence would also depend on whether or not disturbances are correlated, and have constant variances, across time and economies.

${ }^{7}$ For a more detailed discussion of the data, see Higgins et al. (2006) or a data appendix available from the authors upon request. Also, see U.S. BEA (2001) for the personal income data concept and data gathering methods. The original data set contained 3,066 observations. Eight counties, however, were excluded from the data set for lack of data.

${ }^{8}$ The data and their measurement methods are described in detail in "Local Area Personal Income, 19691992" published by the BEA under the Regional Accounts Data, February 2, 2001.
} 


\section{IV. $\beta$-Convergence: Existing Evidence}

Many studies have documented $\beta$-convergence in the U.S. Barro and Sala-iMartin (1992), Evans and Karras (1996a and 1996b), Sala-i-Martin (1996), and Evans (1997a and 1997b) find statistically significant $\beta$-convergence effects using U.S. statelevel data. The present authors use U.S. county-level data to document statistically significant $\beta$-convergence effects across the U.S. (Higgins et al., 2006), and within many individual U.S. states in and of themselves (Young et al., 2006). See Table 1.

Using a consistent three stage least squares (3SLS) estimation method, we estimate the $\beta$-convergence rate to be between 6.3 and 9.8 percent for the U.S. as a whole and, for individual U.S. states, $\beta$-convergence rate point estimates range from just under 4 percent (California) to over 14 percent (Louisiana). (See Table 1, column 3.) Even considering ordinary least squares (OLS) estimates, $\beta$-convergence rate estimates are always positive when significant. (See Table 1, column 2.)

Clearly, considerable evidence supports the existence of $\beta$-convergence, which is a necessary condition for $\sigma$-convergence. Below we explore whether or not $\sigma$ convergence is occurring in the U.S. using the same county-level data that were used by Higgins et al. (2006) and Young et al. (2007).

\section{V. $\sigma$-convergence}

To our knowledge, the only study of U.S. regional $\sigma$-convergence is Tsionas (2000). He examines real Gross State Products (RGSPs) and finds that “...the cross sectional variance has fluctuated very little in the 20-year period from 1977 to 1996" (pp. 235-236). In contrast to Tsionas' data set, our data cover nearly a decade longer. 
Moreover, we have over 3,000 county-level cross-sectional observations while Tsionas uses 50 state-level observations. ${ }^{9}$ It turns out, nevertheless, that our findings are ultimately consistent with Tsionas'.

Table 2 reports 1970 and 1998 cross-sectional standard deviations of (log) income for the entire sample of U.S. counties, and for each of the 50 U.S. states; and the associated p-values for a variance ratio test of the null that the ratio of the two standard deviations is unity (against the two-tailed alternative). The 1998 standard deviation for the full U.S. sample (0.2887) is about 5.8 percent greater than that of $1970(0.2728)$, a difference that is significant at the 1 percent level. In only 2 out of 50 states (Kansas and Oklahoma) is the 1998 standard deviation significantly less than that of 1970 (at the 10 percent level or better). ${ }^{10}$ On the other hand, for 24 states the 1998 standard deviation is significantly larger (at the 10 percent level or better). Thus, for many individual states, as well as for the full U.S., $\sigma$-divergence occurred from 1970 to $1998 .^{11}$

Some have suggested that interpreting measures of dispersion may not be straightforward if the distributions are not unimodal, e.g., Quah (1997) and Desdoigts (1999). However, as Figure 2 demonstrates, for the U.S. county-level data the distribution of income is unimodal for both 1970 and 1998. Figure 2 also allows one to confirm, visually, that $\sigma$-convergence is not present.

\section{Has $\sigma$-divergence Implied Greater Income Inequality?}

Another measure we report that is associated with $\sigma$-convergence (in the sense that it deals with the distribution of income) is the Gini coefficient associated with U.S.

\footnotetext{
${ }^{9}$ As well, Tsionas apparently did not convert RGSPs into per capita measures.

${ }^{10}$ There is one other state where the standard deviation is smaller for 1998: Kentucky.

${ }^{11}$ Of note, of the 24 states with statistically significant increases in standard deviations, 16 of them appear in Table 1 for having statistically significant $\beta$-convergence effects.
} 
counties' 1970 and 1998 (log) incomes: 0.0167 and 0.0165 respectively - a decrease of about 1.2 percent. See Table 3. Recall that Gini coefficient is a number between 0 (perfect equality) and 1 (perfect inequality).

Interestingly, at the county-level, although the distribution of U.S. per capita income became a bit more dispersed from 1970 to 1998 , it became a bit more equal. ${ }^{12}$ However, the change in both the standard deviation and the Gini coefficient are small enough to suggest that both dispersion and equality remained essentially the same.

To try to understand further the evolution of the U.S. county-level income distribution, Table 3 summarizes two additional statistics computed from the 1970 and 1998 income distributions: skewness and kurtosis. From 1970 to 1998 , the skewness of the distribution increased from -0.2244 (to the left) to 1.7240 (to the right). At the same time, kurtosis increased from 3.4334 to 10.3237 , implying that the distribution became more peaked. This suggests that these two effects have been offsetting to a great extent.

\section{Conclusion}

In this paper we show that $\beta$-convergence is a necessary but not sufficient condition for $\sigma$-convergence. We discuss evidence of $\beta$-convergence in the U.S. using county-level data for the 1970 to 1998 period. Using the same data, we show that $\sigma$ convergence was not present during that time period in the U.S. or within a large majority of the individual U.S. states considered separately. In many cases, in fact, statistically significant $\sigma$-divergence is found.

What are we to make of the presence of $\beta$-convergence and evidence of $\sigma$ divergence? If the U.S. was approaching its steady-state income variance from below

\footnotetext{
${ }^{12}$ This statement is not to be confused with one concerning the distributions of U.S. individuals' incomes.
} 
during the 1970 to 1998 period then, based on our discussion in Section II, two interpretations suggest themselves. ${ }^{13}$

First, the initial distribution of income was narrow in 1970 relative to the distribution of balanced growth paths. Second, the 1970 (1998) draw of county-specific shocks had a small (large) sample variance relative to the population variance of shocks.

Going beyond (but still consistent with) the discussion of Section II, another interpretation is that the variance of the balanced growth paths themselves increased. However, one may consider this second interpretation unlikely considering the relative institutional homogeneity of counties across the U.S. and especially within individual states where the same $\beta$-convergence versus $\sigma$-convergence results hold in many cases.

A final - and perhaps least likely - interpretation is that rich counties tend to have balanced growth rates that are higher than those of poor counties. There is little reason to think, however, that the long-run growth rates of technological know-how are different across U.S. counties (and, again, especially within individual states).

In any case, the evolution of skewness and kurtosis suggests that there may be an underlying $\sigma$-convergence for a "majority club" of U.S. counties but that there is another "minority club" that is evolving into a long right-hand tail of the distribution, preventing $\sigma$-convergence in the aggregate.

\footnotetext{
${ }^{13}$ A related issue, which we do not address in this paper directly, is whether or not the cross-sectional distribution of log per capita income is ergodic (Evans, 1996). That would mean that the cross-sectional variance is stationary around a mean or is converging asymptotically toward a constant mean.
} 


\section{References}

Barro, R. J. and Sala-i-Martin, X. X. 1992. Convergence. Journal of Political Economy 100, 223-251.

Desdoigts, A. 1999. Patterns of Economic Development. Journal of Economic Growth 4, $305-330$.

Evans, P. 1996. Using Cross-Country Variances to Evaluate Growth Theories. Journal of Economic Dynamics and Control 20, 1027-1049.

Evans, P. 1997a. How Fast Do Economies Converge? Review of Economics and Statistics 36, 219-225.

Evans, P. 1997b. Consistent Estimation of Growth Regressions. Working Paper, Ohio State University.

Evans, P. and Karras, G. 1996a. Do Economies Converge? Evidence from a Panel of U.S. States. Review of Economics and Statistics 78, 384-388.

Evans, P. and Karras, G. 1996b. Convergence Revisited. Journal of Monetary Economics 37, 249-265.

Friedman, M. 1992. Do Old Fallacies Ever Die? Journal of Economics Literature 30, 2129-2132.

Furceri, D. 2005. $\beta$ and $\sigma$-Convergence: A Mathematical Relation of Causality. Economics Letters 89, 212-215.

Higgins, M. J., Levy, D., and Young, A. T. 2006. Growth and Convergence Across the U.S.: Evidence from County-Level Data. Review of Economics and Statistics 88, forthcoming.

Islam, N. 1995. Growth Empirics: A Panel Data Approach. Quarterly Journal of Economics 110, 1127-1170. 
Mankiw, N. G., Romer, D. H. and Weil, D.N. 1992. A Contribution to the Empirics of Economic Growth. Quarterly Journal of Economics 107, 407-437.

Quah, D. T. 1993. Galton's Fallacy and the Convergence Hypothesis. Scandinavian Journal of Economics 95, 427-443.

Quah, D. T. 1997. Empirics for Growth and Distribution: Stratification, Polarization, and Convergence Clubs. Journal of Economic Growth 2, 27-59.

Sala-i-Martin, X. X. 1996. Regional Cohesion: Evidence and Theories of Regional Growth and Convergence. European Economic Review 40, 1325-1352.

Tsionas, E.G. 2000. Regional Growth and Convergence: Evidence from the United States. Regional Studies 34, 231-238.

U.S. Bureau of Economic Analysis. 2001. Local-Area Personal Income, 1969-1992. Regional Accounts Data.

Young, A.T., Levy, D., and Higgins, M. J. 2007. Heterogeneous Convergence, working paper. 
Figure 1: 3,058 U.S. Counties

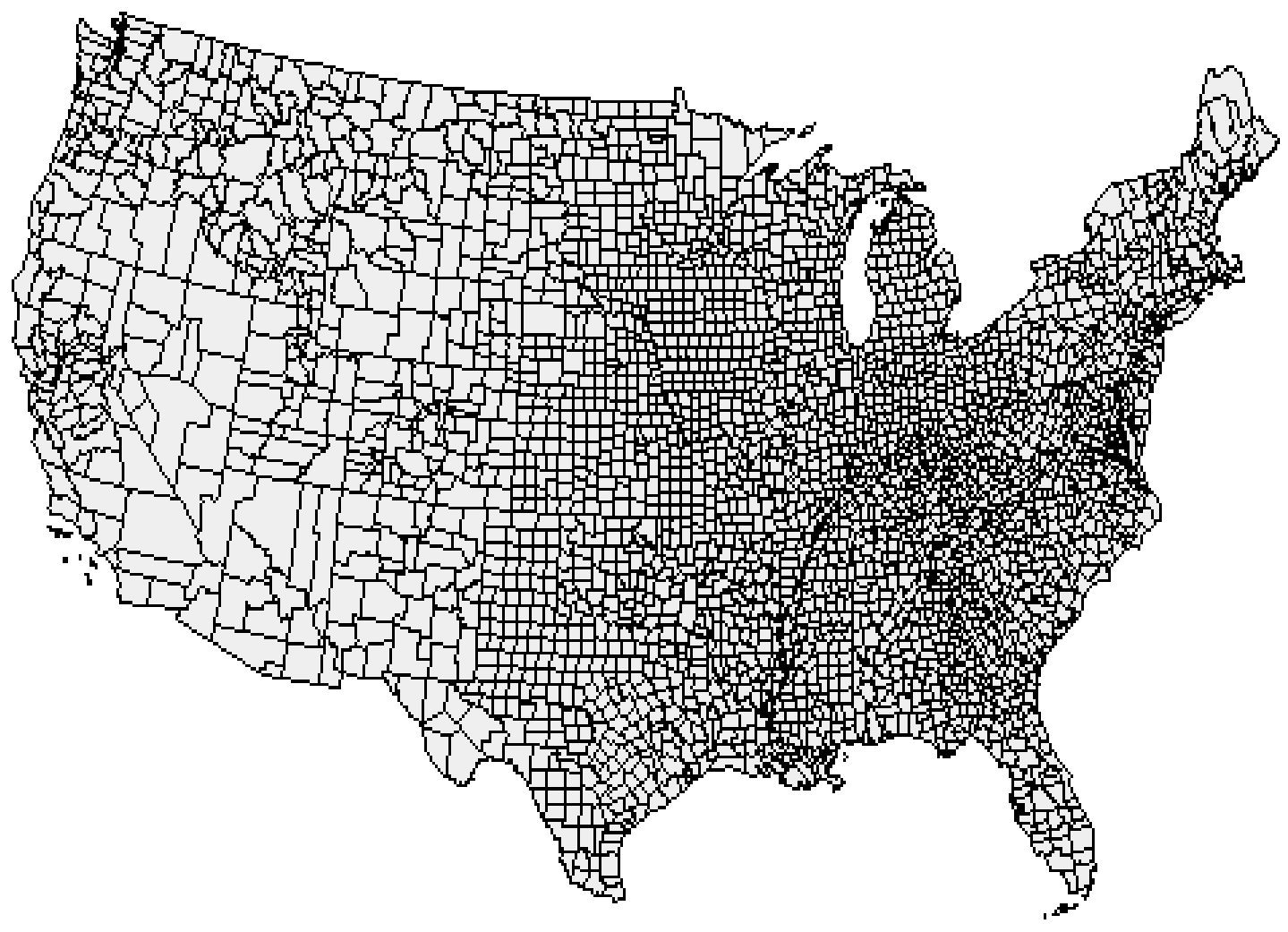

Note: Not shown in the figure, but included in the analysis, are the counties of Alaska and Hawaii.

Figure 2: Distribution of U.S. Counties' Log Per Capita Incomes, 1970 vs 1998

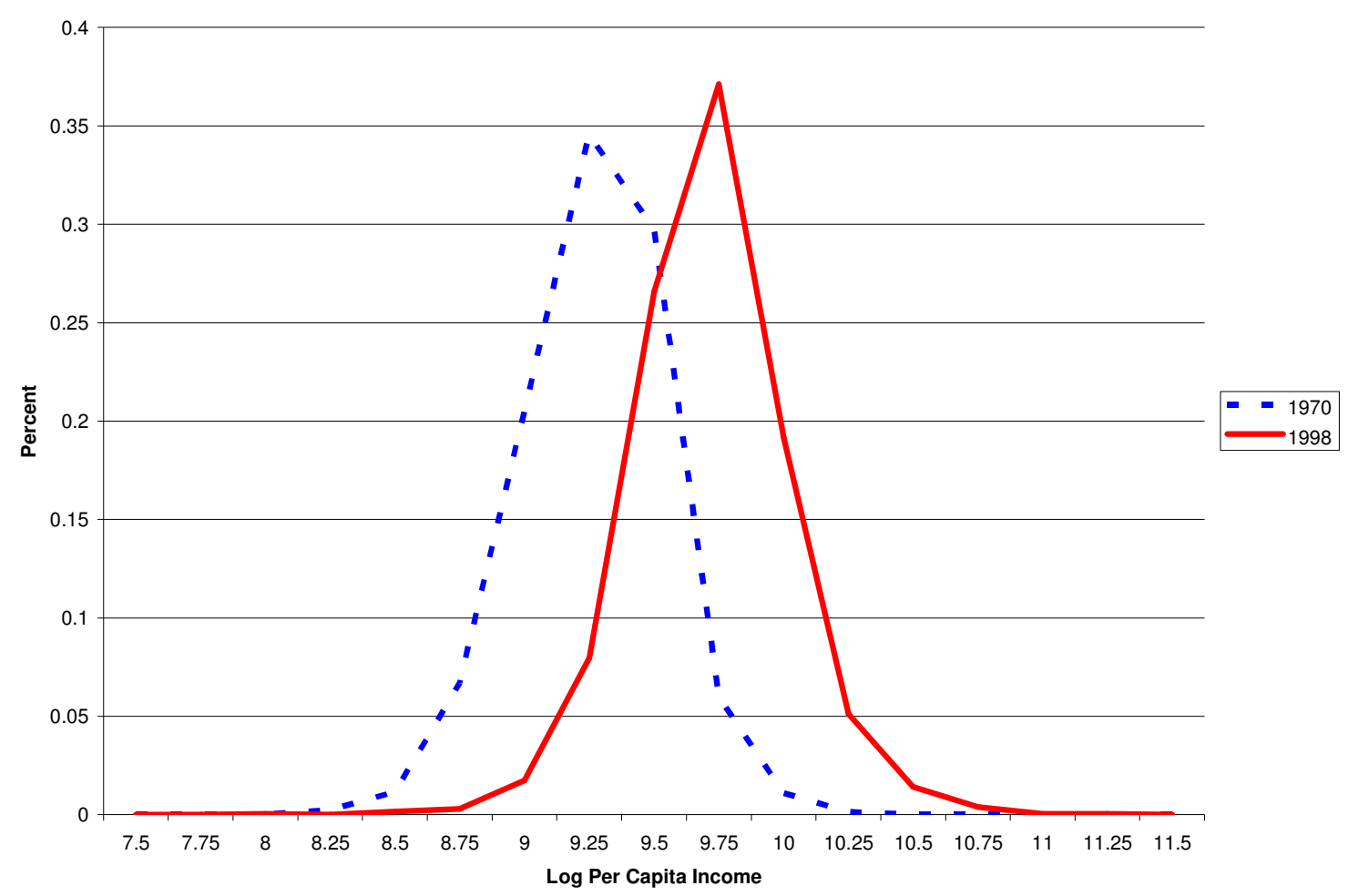


Table 1: Asymptotic Convergence Rates - Point Estimates \& 95\% Confidence Intervals

\begin{tabular}{|c|c|c|}
\hline$\underline{\text { State }}$ & $\underline{\text { Number of Counties }}$ & OLS Estimates \& 95\% C.I. \\
\hline United States & 3,058 & $0.0239(0.0224,0.0255)$ \\
\hline Alabama & 67 & $0.0424(0.0036,0.1080)$ \\
\hline Arkansas & 74 & $0.0479(0.0166,0.1098)$ \\
\hline California & 58 & $0.0457(0.0046,0.1249)$ \\
\hline Colorado & 63 & $0.0166(0.0031,0.0384)$ \\
\hline Florida & 67 & $0.0268(0.0010,0.1109)$ \\
\hline Georgia & 159 & $0.0230(0.0109,0.0413)$ \\
\hline Idaho & 44 & $0.0892(0.0021,0.1566)$ \\
\hline Illinois & 102 & $0.0434(0.0213,0.1168)$ \\
\hline Indiana & 92 & $0.0067(-0.0054,0.0245)$ \\
\hline Iowa & 99 & $0.0570(0.0224,0.1176)$ \\
\hline Kansas & 106 & $0.0560(0.0360,0.1086)$ \\
\hline Kentucky & 120 & $0.0431(0.0233,0.0922)$ \\
\hline Louisiana & 64 & $0.0341(0.0128,0.0955)$ \\
\hline Michigan & 83 & $0.0121(-0.0043,0.0427)$ \\
\hline Minnesota & 87 & $0.0202(0.0053,0.0459)$ \\
\hline Mississippi & 82 & $0.0249(0.0009,0.1509)$ \\
\hline Missouri & 115 & $0.0230(0.0094,0.0452)$ \\
\hline Montana & 56 & $0.0359(0.0099,0.0996)$ \\
\hline New York & 62 & $0.0111(-0.0238,0.0284)$ \\
\hline North Carolina & 100 & $0.0228(0.0078,0.0491)$ \\
\hline North Dakota & 53 & $0.0528(0.0103,0.1247)$ \\
\hline Ohio & 88 & $0.0170(-0.0005,0.0520)$ \\
\hline Oklahoma & 77 & $0.0415(0.0139,0.1136)$ \\
\hline Pennsylvania & 67 & $0.0240(0.0043,0.0707)$ \\
\hline South Carolina & 46 & $0.0142(-0.0147,0.1259)$ \\
\hline South Dakota & 66 & $0.0274(0.0250,0.0300)$ \\
\hline Tennessee & 97 & $0.0287(0.0102,0.0689)$ \\
\hline Texas & 254 & $0.0312(0.0208,0.0458)$ \\
\hline Virginia & 84 & $0.0047(-0.0074,0.0227)$ \\
\hline Washington & 39 & $0.0518(-.0119,0.0971)$ \\
\hline West Virginia & 55 & $0.0040(-0.0184,0.0199)$ \\
\hline Wisconsin & 70 & $0.0270(0.0077,0.0716)$ \\
\hline
\end{tabular}

\begin{tabular}{l} 
3SLS Estimates \& C.I. \\
\hline$-10.0632,0.0981)$ \\
$0.0658(0.0632)$ \\
$0.0931(0.0492,0.1466)$ \\
$0.0738(0.0570,0.1363)$ \\
$0.0375(0.0178,0.0868)$ \\
$0.0759(0.0426,0.1009)$ \\
$0.0767(0.0480,0.1174)$ \\
$0.1043(0.0699,0.1142)$ \\
$0.0913(0.0471,0.1145)$ \\
$0.0537(0.0337,0.1062)$ \\
$0.0622(0.0354,0.1221)$ \\
$0.0574(0.0175,0.0954)$ \\
$0.0639(0.0434,0.1228)$ \\
$0.1054(0.0561,0.1160)$ \\
$0.1555(0.0989,0.1940)$ \\
$0.1152(0.0536,0.1659)$ \\
$0.0454(0.0305,0.0719)$ \\
$0.1405(0.0455,0.1923)$ \\
$0.0817(0.0387,0.1132)$ \\
$0.0865(0.0367,0.1566)$ \\
$0.0465(0.0285,0.0853)$ \\
$0.1302(0.0966,0.1574)$ \\
$0.0761(0.0353,0.1102)$ \\
$0.0503(0.0299,0.1059)$ \\
$0.1152(0.0574,0.1437)$ \\
$0.0705(0.0291,0.1099)$ \\
$0.0960(0.0243,0.1315)$ \\
$0.0406(0.0184,0.1144)$ \\
$0.0681(0.0488,0.1168)$ \\
$0.1170(0.0675,0.1564)$ \\
$0.0703(0.0500,0.1271)$ \\
$0.0845(0.0448,0.1449)$ \\
$0.0634(0.0466,0.0972)$ \\
$0.0390(0.0231,0.0688)$
\end{tabular}

Note: estimates are results originally reported in Higgins et al. (2006) and Young et al. (2007). Following Evans (1997b, footnote 17, p.16), we used $c=1-(1+T \beta)^{1 / T}$ to compute the asymptotic rate of convergence. The confidence intervals (in parentheses) awere obtained in two steps. First, we obtained the end points of the $\beta$ confidence intervals by computing the interval $\beta \pm\left(1.96 \sigma_{\hat{\beta}}\right)$, where $\sigma_{\hat{\beta}}$ is the standard error associated with the estimate of $\beta$. Next, these end-points were substituted into the expression, $c=1-(1+T \beta)^{1 / T}$. If the low value of the confidence interval was less than $-T^{-1}$, then the higher value was set equal to unity. It is clear from the above that confidence intervals computed using this procedure may be asymmetric around the point estimates. 
Table 2: Standard Deviations U.S. Counties' Log Per Capita Incomes, 1970 vs 1998

\begin{tabular}{|c|c|c|c|c|}
\hline$\underline{\text { Region }}$ & $\underline{\text { Number of Counties }}$ & $\begin{array}{c}1970 \text { Per Capita Income } \\
\text { Standard Deviation }\end{array}$ & $\begin{array}{c}1998 \text { Per Capita Income } \\
\text { Standard Deviation }\end{array}$ & p-value \\
\hline United States & 3,058 & 0.2728 & 0.2887 & 0.0017 \\
\hline Alabama & 67 & 0.1949 & 0.2073 & 0.6184 \\
\hline Alaska & 9 & 0.4785 & 0.4798 & 0.9940 \\
\hline Arizona & 9 & 0.2136 & 0.2987 & 0.2400 \\
\hline Arkansas & 74 & 0.1904 & 0.1911 & 0.9900 \\
\hline California & 58 & 0.1646 & 0.3328 & 0.0000 \\
\hline Colorado & 63 & 0.2862 & 0.3282 & 0.2836 \\
\hline Connecticut & 8 & 0.1491 & 0.2411 & 0.2283 \\
\hline Delaware & 3 & 0.2062 & 0.2886 & 0.6759 \\
\hline Florida & 67 & 0.2575 & 0.3360 & $\mathbf{0 . 0 3 2 2}$ \\
\hline Georgia & 159 & 0.2065 & 0.2304 & 0.0850 \\
\hline Hawaii & 4 & 0.1513 & 0.2441 & 0.5555 \\
\hline Idaho & 44 & 0.2003 & 0.2098 & 0.7619 \\
\hline Illinois & 102 & 0.2044 & 0.2263 & 0.3086 \\
\hline Indiana & 92 & 0.1263 & 0.1819 & 0.0006 \\
\hline Iowa & 99 & 0.1089 & 0.1415 & 0.0049 \\
\hline Kansas & 106 & 0.2279 & 0.1804 & 0.0303 \\
\hline Kentucky & 120 & 0.3171 & 0.3151 & 0.9559 \\
\hline Louisiana & 64 & 0.2195 & 0.2389 & 0.5034 \\
\hline Maine & 16 & 0.1233 & 0.2002 & 0.0699 \\
\hline Maryland & 24 & 0.2213 & 0.2927 & 0.1879 \\
\hline Massachusetts & 14 & 0.1355 & 0.2155 & $\mathbf{0 . 0 5 3 3}$ \\
\hline Michigan & 83 & 0.1966 & 0.2663 & 0.0066 \\
\hline Minnesota & 87 & 0.1887 & 0.1963 & 0.7168 \\
\hline Mississippi & 82 & 0.1929 & 0.2464 & 0.0289 \\
\hline Missouri & 115 & 0.2408 & 0.2464 & 0.8072 \\
\hline Montana & 56 & 0.1870 & 0.1911 & 0.8716 \\
\hline Nebraska & 93 & 0.1645 & 0.3475 & 0.0000 \\
\hline Nevada & 17 & 0.1853 & 0.2150 & 0.5594 \\
\hline New Hampshire & 10 & 0.0941 & 0.1444 & 0.2180 \\
\hline New Jersey & 20 & 0.1379 & 0.2768 & 0.0030 \\
\hline New Mexico & 32 & 0.2770 & 0.3055 & 0.5882 \\
\hline New York & 62 & 0.2028 & 0.2995 & 0.0026 \\
\hline North Carolina & 100 & 0.1971 & 0.2184 & 0.3101 \\
\hline North Dakota & 53 & 0.1562 & 0.2361 & 0.0053 \\
\hline Ohio & 88 & 0.1681 & 0.2241 & 0.0078 \\
\hline Oklahoma & 77 & 0.2724 & 0.2180 & 0.0540 \\
\hline Oregon & 36 & 0.1534 & 0.2163 & 0.0458 \\
\hline Pennsylvania & 67 & 0.1692 & 0.2214 & 0.0305 \\
\hline Rhode Island & 5 & 0.0830 & 0.1239 & 0.4568 \\
\hline South Carolina & 46 & 0.1924 & 0.2251 & 0.2962 \\
\hline South Dakota & 66 & 0.2091 & 0.3476 & 0.0001 \\
\hline Tennessee & 97 & 0.2136 & 0.2641 & 0.0408 \\
\hline Texas & 254 & 0.2744 & 0.3035 & 0.0546 \\
\hline Utah & 29 & 0.1732 & 0.2522 & 0.0516 \\
\hline Vermont & 14 & 0.0949 & 0.1934 & 0.0154 \\
\hline Virginia & 84 & 0.2408 & 0.3006 & 0.0490 \\
\hline Washington & 39 & 0.1672 & 0.2213 & 0.0880 \\
\hline West Virginia & 55 & 0.2318 & 0.2436 & 0.7158 \\
\hline Wisconsin & 70 & 0.1940 & 0.2177 & 0.3401 \\
\hline Wyoming & 23 & 0.1623 & 0.2308 & 0.0531 \\
\hline
\end{tabular}

Note: Per capita income figures are in natural log form. P-values are based on a variance ratio test where the null hypothesis is that the value of the ratio of the 1998 to 1970 standard deviations is unity (against the two-tailed alternative). Rows in boldface correspond to cases where the null hypothesis is rejected at the 10 percent level or better. Italics indicate, additionally, significant $\sigma$-convergence. 
Table 3: Summary Statistics for Distribution of U.S. Counties' Log Per Capita Incomes, 1970 vs 1998

$\underline{\text { Statistic }}$

Standard Deviation

Gini Coefficient

Skewness

Kurtosis

Note: per capita income figures are in natural log form.
1970 Per Capita Income 1998 Per Capita Income

$\begin{array}{rl}0.2728 & 0.2887 \\ 0.1666 & 0.1654 \\ -0.2244 & 1.7240 \\ 3.4334 & 10.3237\end{array}$

0.2728

3.4334

10.3237 